\title{
Use of single photon emission computed tomography and magnetic resonance to evaluate central nervous system involvement in patients with juvenile systemic lupus erythematosus
}

\section{G. Prismich ${ }^{1}$, M.O.E. Hilário ${ }^{1}$, C.A. Len ${ }^{1}$, M.T. Terreri' ${ }^{1}$, M.R. Q uaresma ${ }^{1}$, G. Alonso ${ }^{2}$, M.M. Sevillano ${ }^{2}$ and H.M. Lederman ${ }^{2}$}

\author{
IUnidade de Reumatologia Pediátrica, Divisão de Alergia, \\ Imunologia Clínica e Reumatologia, Departamento de Pediatria, \\ Universidade Federal de São Paulo, São Paulo, SP, Brasil \\ 2Divisão de Medicina Nuclear, Departamento de Diagnóstico por Imagem, \\ Universidade Federal de São Paulo, São Paulo, SP, Brasil
}

\section{Correspondence \\ M.O.E. Hilário \\ Al. dos Anapurús, 1370, Apto. 144 04087-004 São Paulo, SP Brasil \\ Fax: + 55-11-570-1590 \\ E-mail: odete@ nox.net}

Publication supported by FAPESP

Received July 17, 2001 Accepted June 11, 2002

\section{Abstract}

The objective of the present study was to identify the single photon emission computed tomography (SPECT) and magnetic resonance (MR) findings in juvenile systemic lupus erythematosus (JSLE) patients with CNS involvement and to try to correlate them with neurological clinical history data and neurological clinical examination. Nineteen patients with JSLE (16 girls and 3 boys, mean age at onset 9.2 years) were submitted to neurological examination, electroencephalography, cerebrospinal fluid analysis, SPECT and MR. All the evaluations were made separately within a period of 15 days. SPECT and MR findings were analyzed independently by two radiologists. Electroencephalography and cerebrospinal fluid analysis revealed no relevant alterations. Ten of 19 patients (53\%) presented neurological abnormalities including present or past neurological clinical history $(8 / 19,42 \%)$, abnormal neurological clinical examination $(5 / 19,26 \%)$, and abnormal SPECT or MR (8/19, $42 \%$ and 3/19, $16 \%$, respectively). The most common changes in SPECT were cerebral hypoperfusion and heterogeneous distribution of blood flow. The most common abnormalities in MR were leukomalacia and diffuse alterations of white matter. There was a correlation between SPECT and MR $(\mathrm{P}<0.05)$. We conclude that SPECT and MR are complementary and useful exams in the evaluation of neurological involvement of lupus.

\section{Introduction}

In 16 to $52 \%$ of the patients with juvenile systemic lupus erythematosus (JSLE), a wide spectrum of neuropsychiatric manifestations may occur at any time during the course of
Key words

- Systemic lupus

erythematosus

- Central nervous system

- Single photon emission

computed tomography

- Magnetic resonance

- Neurological clinical history the disease (1-7). The diagnosis of neurological involvement in JSLE is usually difficult due to the low sensitivity of the complementary exams. Among these, computed tomography (CT) and magnetic resonance (MR) should be highlighted, both being use- 
ful in the detection of anatomical alterations of the central nervous system (CNS). More recently, single photon emission computed tomography (SPECT) has been used to evaluate cerebral perfusion in children with lupus $(8,9)$. Szer et al. (8), studying five JSLE patients with severe clinical signs of neurological involvement, observed SPECT abnormalities in all of them, but MR alterations in only three. Reiff et al. (9) also studied the SPECT and MR of ten JSLE patients with CNS involvement and found abnormal SPECT changes in all patients and MR alterations in six of ten patients.

The purpose of the present study was to identify the SPECT and MR findings in JSLE patients with CNS involvement and to try to correlate them with neurological clinical history data and neurological clinical examination.

\section{Patients and Methods}

Nineteen patients (16 girls and 3 boys) were selected consecutively at the pediatric rheumatology outpatient clinic of a university hospital. The inclusion criteria were diagnosis of JSLE according to the classification criteria of the American College of Rheumatology (1982) (10) and age under 16 years. Consent to participate in the study was obtained from parents or persons responsible for each child or adolescent. The research was approved by the Hospital Ethics Committee.

Mean age at onset was 9.2 years and mean disease duration until the time of the investigation was 4.2 years. During the study, 12 patients $(63 \%)$ presented some degree of clinical lupus activity, including malar rash, vasculitis, arthritis and nephritis. Fifteen patients were receiving steroids and 14 were receiving immunosuppressive drugs (azathioprine, methotrexate or cyclophosphamide) at the time of the SPECT and MR investigation.

All selected patients were submitted to neurological clinical history, neurological examination, electroencephalography, cerebrospinal fluid analysis, SPECT, and MR. Demographic and clinical data were obtained by a pediatric rheumatologist. Parents/patients were asked about the neuropsychiatric manifestations which had been observed since the onset of the disease. A pediatric neurologist performed neurological examination. Any neurological abnormality found in routine neurological exams, including signs of pyramidal or extrapyramidal involvement, and cerebellar, upper cortical function, neuromuscular, or peripheral abnormalities was considered to be "neurological abnormality".

\section{Single photon emission computed tomography}

All patients received an intravenous injection of ${ }^{99 m}$ technetium-ethylenedicysteinate-dimer $\left({ }^{99 \mathrm{~m}} \mathrm{Tc}-\mathrm{ECD}\right)$ at the dose of 740 $1110 \mathrm{MBq}(20-30 \mathrm{mCi})$, with scanning of the images being initiated after 10 to $15 \mathrm{~min}$. A gamma camera equipped with a single rotating head was used. The images were scanned with a 64 x 64 matrix, without zoom, with $6^{\circ}$ angles, comprising $360^{\circ}$, for a total of 60 images, with a scanning time of $20 \mathrm{~s}$ per angle and total time of $20 \mathrm{~min}$. The images were fed into a computer and reconstructed by applying a recovery filter (Butterworth) with a cut frequency of 0.25 and a threshold of 4 , in the axial, sagittal and coronal projections with a thickness of $0.9 \mathrm{~cm}$, presented later on the screen for interpretation. The images were analyzed by three independent investigators. The examination was considered normal when there was a symmetrical and homogeneous concentration of ${ }^{99 \mathrm{~m}} \mathrm{Tc}$ ECD in both cerebral hemispheres, and abnormal in the presence of asymmetry in the distribution of the ${ }^{99 \mathrm{~m} T c-E C D}$ in the whole hemisphere or in some lobe, and/or when there were focal areas of low tracer concentration. The examinations were considered 
normal if they demonstrated increased activity in the occipital cortex (visual). This finding is considered to be an artifact or a variation of normal data.

\section{Magnetic resonance}

The exam was carried out in two stages, i.e., with and without contrast. Scanning was performed on 5-mm thick sagittal, axial and coronal slices using a Philips Gyroscan S 15 instrument of 1,5 Tesla. In the phases with and without contrast, the sagittal slices were scanned in $\mathrm{T} 1$ with a relaxation time (RT) of $775 \mathrm{~ms}$ and an echo time (ET) of $20 \mathrm{~ms}$. The axial slices were scanned with proton density in T2 with RT between 2500 and 3000 $\mathrm{ms}$ and ET between 30 and $90 \mathrm{~ms}$, and in T1, with the same patterns as the sagittal images. The paramagnetic contrast used was Magnevistan ${ }^{\circledR}$ (dimegluminic gadopentetate, 1 ml-469 mg; Schering, São Paulo, SP, Brazil). The MR images were independently analyzed by two radiologists who were not aware of patient clinical history or diagnosis.

\section{Complementary tests}

All patients were submitted to electroencephalography and cerebrospinal fluid analysis, both performed by a neurologist.

\section{Statistical analysis}

The Kappa value was calculated to evaluate the concordance among the imaging exams (11) and the Spearman correlation coefficient was used to correlate the neurological clinical history/patient neurological clinical examination with SPECT and MR findings (12). Two-tailed tests were used, with the alpha probability fixed at $5 \%$.

\section{Results}

Electroencephalography and cerebrospinal fluid analysis were normal. Ten of 19 patients $(53 \%)$ presented neurological abnormalities including present or past neurological clinical history $(8 / 19,42 \%)$, abnormal neurological clinical examination $(5 / 19$, $26 \%)$, and abnormal SPECT $(8 / 19,42 \%)$ or MR (3/19, 16\%). History, neurological clinical examination, SPECT and MR findings are presented in Table 1 .

The most common changes observed in the SPECT were cerebral hypoperfusion (Figure 1A) and heterogeneous distribution of blood flow (Figure 1B). The most common MR abnormalities were leukomalacia (Figure 1C) and diffuse alterations of white matter.

We observed a significant correlation between SPECT and MR ( $\mathrm{P}=0.032$, Spearman correlation coefficient). The Kappa test also showed a correlation between the imaging exams $(\mathrm{Z}=2.477, \mathrm{P}<0.02)$.

\section{Discussion}

The neurological clinical history and examination are still considered to be the "gold" standard for the determination of CNS involvement in JSLE patients. In the present study, the neurological clinical history was positive in 8/19 patients; however, in two patients who presented abnormalities in both SPECT and MR (patients \#8 and \#9, Table 1), no neurological sign or symptom was observed. Our findings are in agreement with those reported by Russo et al. (13). In their study, SPECT was performed on 30 JSLE patients, 20 of them presenting positive clinical CNS involvement. Diffuse SPECT abnormalities were observed in $50 \%$ of the patients without clinical signs of CNS involvement. Falcini et al. (14) studied the SPECT of 14 JSLE patients and detected abnormalities in $2 / 7$ patients without neurological clinical signs or symptoms. After 6 months, SPECT was performed again on the same patients and signs of imaging improvement were observed. These findings suggest that some JSLE patients may present sub- 
Table 1. Past and present neurological clinical history, neurological clinical examination, single photon emission computed tomography (SPECT) and magnetic resonance (MR) of J SLE patients who have presented some degree of CNS involvement since the onset of the disease $(N=10)$.

\begin{tabular}{|c|c|c|c|c|c|}
\hline Patient \# & $\begin{array}{l}\text { Age at onset } \\
\text { (years)/gender }\end{array}$ & History & $\begin{array}{l}\text { Neurological } \\
\text { clinical } \\
\text { examination }\end{array}$ & SPECT & $M R$ \\
\hline 1 & $8 / F$ & $\begin{array}{l}\text { Behavior } \\
\text { alteration }\end{array}$ & Tremor & $\begin{array}{l}\text { Hypoperfusion of left } \\
\text { frontoparietal lobe }\end{array}$ & Normal \\
\hline 2 & $11 / \mathrm{F}$ & $\begin{array}{c}\text { Transverse } \\
\text { myelitis, } \\
\text { chorea, CVA }\end{array}$ & Normal & Normal & Normal \\
\hline 3 & $8 / F$ & CVA, chorea & $\begin{array}{c}\text { Decrease of } \\
\text { muscular strength } \\
\text { and deep reflexes } \\
\text { (left side) }\end{array}$ & $\begin{array}{c}\text { Hypoperfusion of } \\
\text { left frontoparietal } \\
\text { lobe and right } \\
\text { parietal lobe }\end{array}$ & $\begin{array}{l}\text { Leukomalacia of right } \\
\text { temporofrontoparietal } \\
\text { lobe, cerebellar and } \\
\text { cortical atrophy }\end{array}$ \\
\hline 4 & 9/M & Headache & Tremor & $\begin{array}{l}\text { Hypoperfusion of right } \\
\text { temporal lobe and } \\
\text { heterogenous flow }\end{array}$ & Normal \\
\hline 5 & $7 / F$ & Seizures & Tremor & $\begin{array}{l}\text { Hypoperfusion of left } \\
\text { temporofrontoparietal } \\
\text { lobe }\end{array}$ & Normal \\
\hline 6 & $10 / \mathrm{F}$ & Seizures & Paresthesia & Normal & Normal \\
\hline 7 & $8 / M$ & $\begin{array}{l}\text { Headache, } \\
\text { nystagmus, } \\
\text { CVA, facial } \\
\text { palsy }\end{array}$ & Normal & $\begin{array}{l}\text { Hypoperfusion of left } \\
\text { temporoparietal lobe }\end{array}$ & $\begin{array}{c}\text { Focal leukomalacia of } \\
\text { parietal lobe } \\
\text { (posterior), cortical } \\
\text { atrophy }\end{array}$ \\
\hline 8 & $11 / \mathrm{F}$ & Normal & Normal & $\begin{array}{c}\text { Hypoperfusion of left } \\
\text { temporoparietal lobe } \\
\text { and heterogenous } \\
\text { flow }\end{array}$ & $\begin{array}{c}\text { Diffuse abnomalities } \\
\text { of white matter, } \\
\text { cerebellar and cortical } \\
\text { atrophy }\end{array}$ \\
\hline 9 & $8 / F$ & Seizures & Normal & $\begin{array}{l}\text { Hypoperfusion of left } \\
\text { frontoparietal lobe }\end{array}$ & Normal \\
\hline 10 & $12 / F$ & Normal & Normal & Heterogenous flow & Normal \\
\hline
\end{tabular}

Figure 1. Most common changes observed in the SPECT: cerebral hypoperfusion (A) and heterogeneous distribution of blood flow (B). The most common MR abnormalities were leukomalacia (C) and diffuse alterations of white matter.
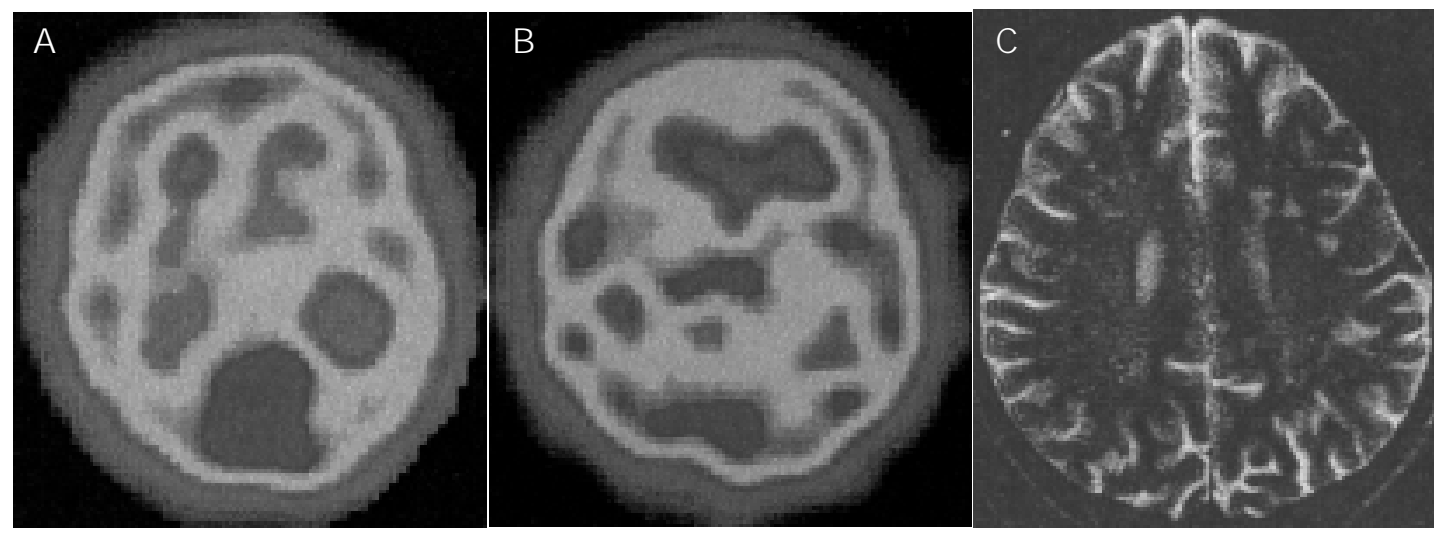
clinical CNS involvement which can be detected by SPECT.

Some literature reports have demonstrated an agreement between the clinical and SPECT findings $(8,9,15,16)$. Reiff et al. (9) studied 11 JSLE patients, all of them with active neurological disease, and observed SPECT alterations in $100 \%$ of cases. These investigators concluded that SPECT is sensitive in detecting CNS involvement only in the acute phase, e.g., up to 4 months after the onset of neurological manifestations. Szer et al. (8) followed up five children with lupus and CNS involvement for up to one year after the onset of symptoms using SPECT, MR and CT. SPECT showed blood flow abnormalities in all patients, while MR and CT detected anatomical alterations in only three.

In the present study, eight of 19 patients (42\%) presented signs and/or clinical symptoms of CNS involvement during the course of the disease. Six of these eight patients presented SPECT alterations and only three showed MR changes. Just one patient presented clinical manifestations of CNS involvement by the time SPECT and MR were performed. These data indicate that in some patients both SPECT and MR remain abnormal even after the acute phase of CNS involvement.

\section{References}

1. Gold AP \& Yahr MD (1960). Childhood lupus erythematosus: a clinical and pathological study of the neurological manifestations. Transactions of the American Neurological Association, 85: 96-102.

2. Meislin AG \& Rothfield N (1968). Systemic lupus erythematosus in childhood. Analysis of 42 cases, with comparative data on 200 adult cases followed concurrently. Pediatrics, 42: 37-49.

3. Yancey $\mathrm{CL}$, Doughty RA \& Athreya BH (1981). Central nervous system involvement in childhood systemic lupus erythematosus. Arthritis and Rheumatism, 24: 1389-1395.

4. Cassidy JT \& Petty RE (1995). Systemic lupus erythematosus. In: Cassidy JT \&
Even though headache is a frequent complaint in lupus patients, its physiopathology is still unclear. It is plausible to think that alterations of cerebral blood flow can explain this symptom. In a study on 19 children and adolescents with migraine, SPECT showed hypoperfusion areas in $3 / 6$ patients with classic migraine and in $1 / 3$ patients with hemiplegic migraine (15). Steinlin et al. (6) studied nine JSLE children with headache; four of them were submitted to SPECT and abnormalities were found in only one. In our study, we observed SPECT changes in two patients reporting headache. However, on the basis of our data and of literature reports, it is not possible to be sure if SPECT findings are related to the cause or the consequence of flow alterations.

On the basis of our results, we may conclude that a detailed neurological clinical history continues to be a fundamental tool in the diagnosis of CNS involvement. SPECT and MR may be complementary and useful exams in the evaluation of neurological involvement in lupus.

\section{Acknowledgments}

We thank Professors Yara Juliano and Neil Ferreira Novo for the statistical analysis.
Petty RE (Editors), Textbook of Pediatric Rheumatology. W.B. Saunders Company, Philadelphia, PA, USA, 260-322.

5. Parikh S, Swaiman KF \& Kim Y (1995). Neurologic characteristics of childhood lupus erythematosus. Pediatric Neurology, 13: 198-201.

6. Steinlin MI, Blaser SI, Gilday DL, Eddy AA, Logan WJ , Laxer RM \& Silverman ED (1995). Neurologic manifestations of pediatric systemic lupus erythematosus. Pediatric Neurology, 13: 191-197.

7. Tucker LB, Menon S, Schaller JG \& Isenberg DA (1995). Adult- and childhoodonset systemic lupus erythematosus: a comparison of onset, clinical features, serology, and outcome. British J oumal of
Rheumatology, 34: 866-872.

8. Szer IS, Miller J H, Rawlings D, Shaham B \& Bernstein B (1993). Cerebral perfusion abnormalities in children with central nervous system manifestation of lupus detected by single photon emission computed tomography. J ournal of Rheumatology, 20: 2143-2148.

9. Reiff A, Miller J, Shaham B, Bernstein B \& Szer IS (1997). Childhood central nervous system lupus; longitudinal assessment using single photon emission computed tomography. J ournal of Rheumatology, 24: 2461-2465.

10. Tan EM, Cohen AS, Fries J F, Masi AT, McShane DJ , Rothefield NF, Schaller J G, Talal N \& Winchester RJ (1982). The 1982 
revised criteria for the classification of systemic lupus erythematosus. Arthritis and Rheumatism, 25: 1271-1277.

11. Landis J R \& Kock CG (1977). The measurement of observer agreement for contrasts among multinomial populations. Biometrics, 33: 159-174.

12. Siegel S \& Castellan J r NJ (1988). Nonparametric Statistics. 2nd edn. McGrawHill, New York, NY, USA, 399.

13. Russo R, Gilday D, Laxer RM, Eddy A \&
Silverman ED (1998). Single photon emission computed tomography scanning in childhood systemic lupus erythematosus. J oumal of Rheumatology, 25: 576-582.

14. Falcini $F$, De Cristofaro MTR, Ermini $M$, Guarnieri M, Massai G, Olmastroni M, Masi A, Pupi A \& Meldolesi U (1998). Regional cerebral flow in juvenile systemic lupus erythematosus: a prospective SPECT study. J ournal of Rheumatology, 25: 583-588.
15. Battistella PA, Ruffilli R, Dalla Pozza F, Pitassi I, Casara GL, Boniver C, Suppiej A, Bendagli B \& Condini A (1990). 99mTC HMPAO SPECT in pediatric migraine. Headache, 30: 646-649.

16. Kao CH, Lan J L, Changlai SP, Liao KK, Yen RF \& Chieng PU (1999). The role of FDGPET, HMPAO-SPET and MRI in the detection of brain involvement in patients with systemic lupus erythematosus. European J oumal of Nuclear Medicine, 26: 129-134. 